\title{
Determining the Role of Hand Feeding Practices in Accidental Shark Bites on Scuba Divers
}

\author{
Clua $\mathrm{EE}^{*}$ and Torrente $\mathrm{F}$ \\ Laboratoire d'Excellence «CORAIL» USR 3278 CNRS - EPHE, CRIOBE, BP1013, 98729 Papetoai, Moorea, \\ Polynésie Française
}

*Corresponding author: Clua E, Laboratoire d'Excellence «CORAIL» USR 3278 CNRS -Ecole Pratique des Hautes Etudes, CRIOBE, BP1013, 98729 Papetoai, Moorea, Polynésie Française, Tel : +689 87229602, E-mail: Eric.clua@gmail.com

Citation: Clua EE, Torrente F (2016) Determining the Role of Hand Feeding Practices in Accidental Shark Bites on Scuba Divers. J Forensic Sci Criminol 4(1): 102. doi: 10.15744/2348-9804.4.102

Received Date: September 21, 2015 Accepted Date: February 24, 2016 Published Date: February 25, 2016

\begin{abstract}
Introduction: Shark-based ecotourism is significantly developing around the world, often without appropriate management of risk. This activity involves a risk of accidental bites on divers that can be quite severe or even fatal.

Objectives: To determine if ecotourism companies' liability can be engaged in the context of bites on scuba divers in presence of hand-feeding practices, supporting the legitimacy of financial compensation for the victims.

Methods: We analyzed the development from the mid-eighties to 2010 of shark-based ecotourism through artificial provisioning practices in Moorea Island (French Polynesia) and more specifically the features and motivation of two bites on divers by Sicklefin Lemon sharks.

Results: The specific practice of hand-feeding can be considered as a facilitating factor for accidental bites on divers, potentially involving the diving operator's responsibility.

Conclusions: Our findings should support the technical work of experts that might be called in such cases.

Keywords: Diving ecotourism safety; Risk management; Marine predator provisioning; Agonistic deviant behavior; Sicklefin Lemon shark; Negaprion acutidens
\end{abstract}

\section{Introduction}

Over the past two decades, shark-based ecotourism has significantly developed through more than 80 ecotourism operations throughout the world, in at least 40 different countries mainly in tropical and sub-tropical oceans [1,2]. For most of these countries, this type of ecotourism represents a critical source of income. In french Polynesia (Eastern-Central Pacific), environmental economists [3] have shown that any one of the 13 lemon sharks most often observed at a feeding site in Moorea (Windward islands) made an average contribution to the local economy of around USD 316699 per year, contributing to a total income of US\$5.4 million. However, given their elusive nature, encountering these shy species cannot be guaranteed, and artificial provisioning, generally called 'shark-feeding', is necessary to ensure impressive aggregations of animals in specific places thereby allowing close interactions with divers and snorkellers [1].

The general concept of 'shark-feeding' mainly applies to carnivorous shark species, and actually encompasses several techniques. The most common technique for allowing tourists to see Great White sharks (Carcharodon carcharias) and pelagic sharks such as the Silky (Carcharhinus falsiformis), Galapagos (C. galapagensis), Sandbar (C. plumbeus) and Tiger sharks (Galeorcerdo cuvier), either from boats or through scuba (and cage) diving, is known as 'chumming' [4,5,6]; it is also known in Australia as 'berleying' $[7,8]$. Chumming or berleying involves placing blood and/or liquidized tiny fish parts in the water to create an oily slick that sharks can sense and follow to the boat (or the divers) [5]. In that case, animals never get any food reward. Real 'feeding' intends to provide the animals with a variable quantity of large pieces of fish or meat that they are allowed to consume at a given stage of the session $[4,9,10]$. These are usual techniques, also called 'baiting', used with Grey Reef (C. amblyrhynchos and C. perezi), Lemon (Negaprion brevirostris and N. acutidens), Blacktip (C. melanopterus) and Bull sharks (C. leucas). Whatever the technique, deliberate and longterm feeding of animals is suspected to generate problems for both animals and humans [4]. From the animal perspective, it may alter the natural behavioural patterns of sharks, generating detrimental effects for the animal themselves and the marine ecosystem; from the human perspective, it can increase the shark's level of aggression, leading to agonistic behaviours, including serious bites [9]. In that respect, based on an analysis of 54 cases of shark attacks that occurred between 1979 and 2001 in French Polynesia (Eastern Pacific), 25 cases (45\%) happened during shark feeding activities [11]. In some cases, the victim may consider that the accident is the legal responsibility of the dive operator and seek financial compensation. Experts may then be employed to provide technical support for the legal process. 


\section{Objectives}

In the present study, we use two case studies in French Polynesia to describe the features of accidental shark bites on scuba divers and discuss how the practice of hand feeding could constitute a major driving factor for explaining such accidents. This information may assist the work of experts that might be employed to for determine whether shark bites in the framework of artificial provisioning should involve the liability of dive operators or just be considered as a consequence of the natural behaviour of a marine predator, potentially harmful to humans.

\section{Materials and Methods}

\section{Description of the study sites}

The two main sources of income for a population of 260,000 inhabitants are the black pearl oyster industry and tourism with an average of 170,000 visitors per year. Reef scuba-diving represents around 20\% of the leisure activities of tourists, but was threatened during the mid-and late 1990s after several catastrophic events degraded reefs, promoting the development of sharkbased ecotourism. The most common reef shark species usually involved in ecotourism are present in French Polynesia, in particular the small-bodied mauri (local name for the Blacktip shark) and the medium-bodied raira (local name for the Grey Reef shark). In their search for impressive larger species for tourist divers, professional ecotourism operators focus on the tore-tore (local name for the Tiger shark) but mainly on the arava (local name for the Sicklefin Lemon shark) which is in higher densities and more sedentary.

\section{Characteristics of the Sicklefin Lemon shark}

The Sicklefin Lemon shark Negaprion acutidens (Rüppell, 1837) is a tropical inshore large ( $\leq 340 \mathrm{~cm}$ total length), stout shark, with a yellowish brown color above, paler below [12]. It is a fish-eating shark, potentially dangerous because of its large size, powerful jaws and dagger-like teeth (Figure 1); it is normally inoffensive and sluggish but very aggressive when provoked [13]. Adults are rather solitary in normal condition, except during the mating season when males diligently follow females. Sicklefin Lemon shark species cannot be considered as gregarious as other sharks species involved in shark feeding operations, such as the Grey Reef shark which naturally aggregate in large schools in confined areas [13].

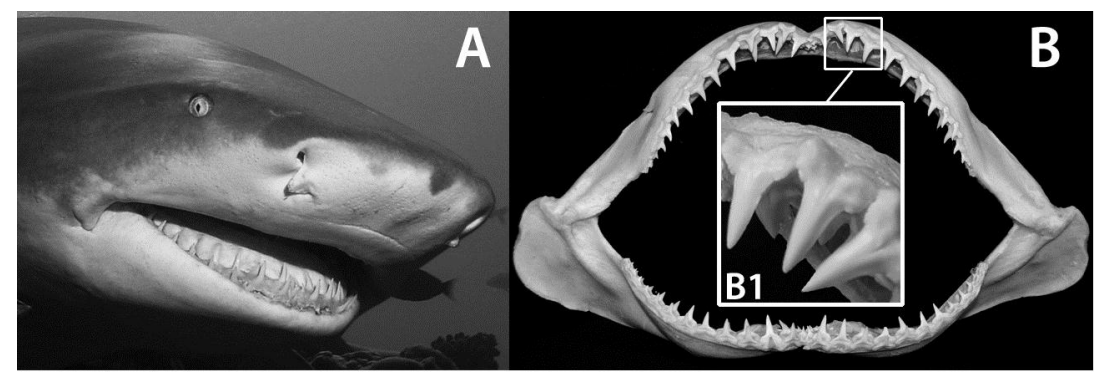

Figure 1: (A) Stout head and large mouth of the Sicklefin Lemon shark (Negaprion acutidens). (B) Jaw of the Sicklefin Lemon shark with a close up (B1) on the dagger-like teeth from the upper jaw that can inflict severe bites. The Lemon shark is homodont as upper and lower teeth have the same shape that function by tearing out flesh rather than cutting such as the teeth from the upper jaw of other sharks i.e. Bull shark (Carcharhinus leucas) or Grey Reef shark (C. amblyrhynchos)

Through high speed cinematography and electromyography, marine biologists [14] thoroughly described the biting mechanisms of the Atlantic Lemon shark N. brevirostris. Given the high morpho-anatomical similarity of the two sister species, we consider as valid this description for the Sicklefin Lemon shark from the Indo-Pacific. Two types of biting events were differentiated during feeding: (1) food ingestion by ram feeding (when the piece would be small enough for a direct swallowing) and (2) food manipulation (which immediately follows ingestion bites and during which the food is usually repositioned or cut by the teeth before swallowing the different parts). Both types of bites have similar motor and kinematic patterns including a preparatory phase, an expansive phase, and a compressive phase characterized by elevation of the mandible and depression of the head. These phases mobilize more than 12 different muscles and ligaments. The average duration of an ingestion bite in Lemon sharks is however very quick (with a range between 160 to $730 \mathrm{~ms}$ ) [15]. In comparison the same type of bite for an adult White shark (Carcharodon carcharias) would take between 750 and $1708 \mathrm{~ms}$ [16].

\section{Data collection and analysis}

The Sicklefin Lemon shark behaviour in the context of shark provisioning was collectively and individually monitored through more than 1,000 hours of diving observation, in the framework of a long-term study (2005-2010) implemented on the island of Moorea [9,17]. This study was conducted in close cooperation with a professional dive master (involved in shark feeding from 1997 to 2010) who was part of this same study and also the victim of the two bites that are described hereafter. Photographs of the bites were collected and this person was interviewed in order to get information allowing an analysis of the motivation and type of bites. Two other professional dive masters, directly involved in the introduction and development of shark feeding on Moorea island, were also interviewed in order to determine the chronology of shark feeding in Moorea island (from the very beginning), the shark feeding effort through time, the potential changes in feeding practices and the contribution of the different shark species to feeding operations and potential bites. 


\section{Results}

\section{History of shark feeding in Moorea Island}

Moorea is a high island with an encircling coral reef barrier where shark feeding was developed by a single diving operator in 1986, joined by a second operator in 1988. The first shark species to be aggregated by feeding on the outer slope were the Black tip and Grey Reef sharks. The Lemon shark only started to aggregate by 1992 in a specific place around Opunohu Bay (North of Moorea Island, [9] for more details). Between 1990 and 1995, two more diving operators established operations, one of them implementing feeding. By 2004 up to 2010, there were seven diving operators working in the same area, including six that were implementing artificial provisioning. A previous study on the economic value of shark-based ecotourism in Moorea island showed that around 4 000 local and 3000 international divers were coming by the mid-2000s to Moorea every year with the specific purpose of viewing sharks, and an additional 5600 were making the decision to dive with sharks while they were staying in Moorea [3].

\section{Description of the feeding practices of large sharks in Moorea Island}

When shark feeding for ecotourism started in the late 1980s, some food (mainly fish waste) was left on the bottom of the outer slope, dispersed across the reef patches in depths of around 15 meters. As sharks became less shy, hand feeding was developed after a couple of years in order to maintain the underwater spectacle. The dive master lay on the bottom with a bag from which he extracted food, piece by piece, wearing a mesh glove on the operating hand. The tourist divers were positioned in circle around the feeder, at a few meters of distance. When Lemon sharks started to aggregate by the early 1990s, they were hand fed from the very beginning, at depths between 15 and 20 meters (Figure 2A). In the early 2000s, at least four diving operators were hand feeding Lemon sharks, mainly with tuna discards; however, the total amount of food provided on a daily basis would rarely exceed $10 \mathrm{~kg}$ and the aggregation would encompass over 30 different Lemon sharks over a year, with sometimes up to 10-12 individuals in one session [13].

Following an accidental bite in 2004 (see hereafter the description of accident 1), the major diving operator in Moorea stopped hand feeding. This practice was however still implemented by at least another diving operator until 2008. Instead of hand feeding, the major operator was storing the fish waste in a cage that was either dropped from the boat few minutes before the start of the dive, or brought down by the dive master just before the arrival of the tourist divers (Figure 2B). Once on the bottom, the tourist scuba-divers were positioned several meters from the cage, anticipating the arrival of the sharks or just observing them already moving around. After a while the cage was opened by the dive master, and the food was released either in a single motion or piece by piece on the bottom. In parallel to this new practice, a third operator was introducing odours ('chumming') in the same area by storing fish flesh in a circular plastic container with small holes to allow the dispersal of the olfactory stimulus. This container hung from a rope from the diving boat, between one and four meters above the bottom, attracting the Lemon sharks in the water column to a convenient position for observation by divers (Figure $2 \mathrm{C}$ ).
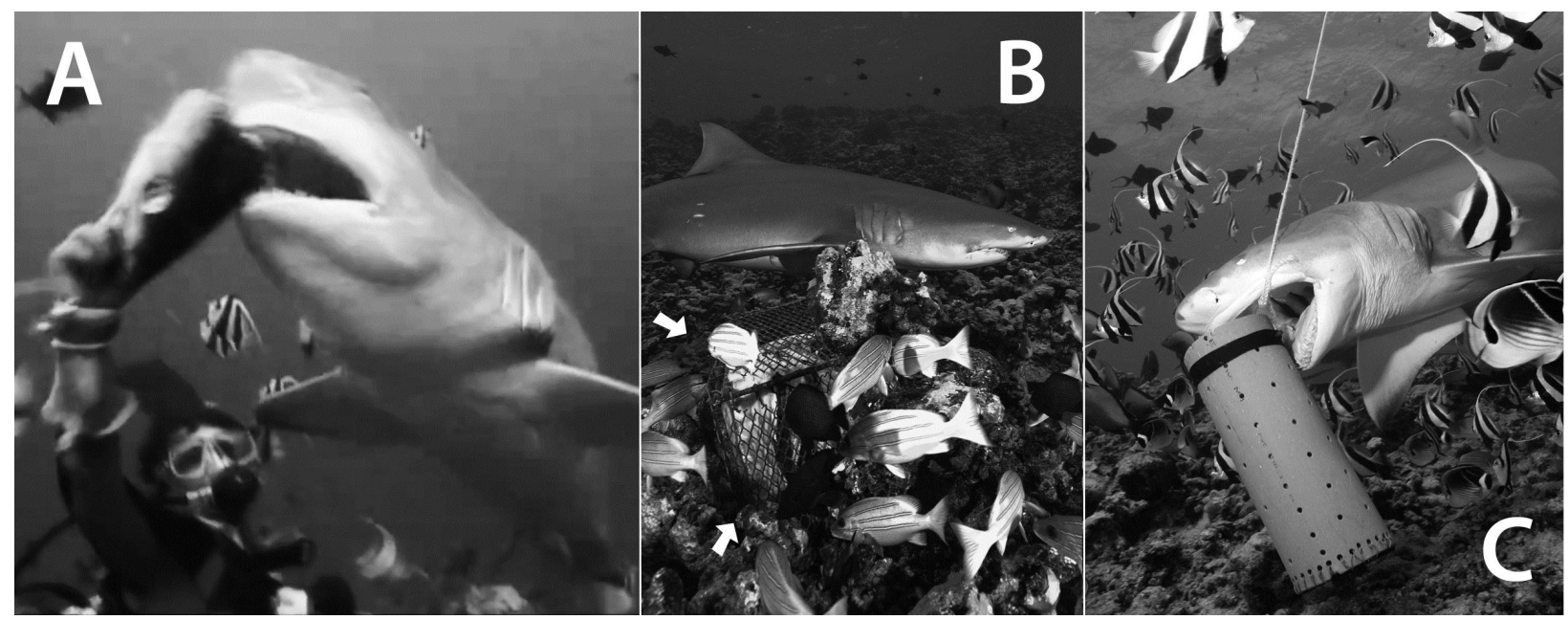

Figure 2: (A) Lemon shark hand feeding (here with a tuna head) as was implemented in Moorea island from 1992. (B) Storage of bait in a cage (indicated by arrows) as it was practised by the main diving center in Moorea after the 2004 accidental bite. (C) Storage of the bait in a porous plastic container hanging from the diving boat in the water column may increase shark aggressiveness

\section{Description of the shark bites}

Accident 1 occurred at the Opunohu site on March 2004 and involved a dive master. The bite occurred during a morning dive (ca. 08:00), which was planned for the production of a shark feeding video. Conditions were difficult, with a strong northern swell and poor visibility $(<5 \mathrm{~m})$. The diving group was at a depth of $18 \mathrm{~m}$ and comprised of three divers including a dive master in charge of feeding, a cameraman and a third diver. Three male Lemon sharks were attracted by the feeding stimulus (tuna heads in a mesh bag). The dive master was giving the tuna heads to the sharks with his right hand, protected by a steel-mesh glove. In order to record optimal images of shark feeding, the dive master was positioning himself to get the sharks coming from his left side. He 
was then using his right hand to exhibit the tuna head and when the shark was almost in contact, he used his unprotected left hand to grab the right pectoral fin, to keep the animal at a safe distance and avoid any contact. During a feeding attempt, a $2.3 \mathrm{~m}$ TL male shark rotated its head rapidly and bit his left hand, before releasing it few seconds later. The bite ripped his suit, removed his watch and left by deep wounds on the left forearm and hand (Figure 3A). Tissue loss was not substantial, hence the physical consequences were minor and the dive master was able after surgery to use the hand again without limitation.

Accident 2 also occurred at the Opunohu site on June 2008 and involved the same dive master. The bite took place during a morning dive ( $\mathrm{ca} .08: 00)$ as the victim was involved in an underwater photo session, at a depth between 15 and $20 \mathrm{~m}$. The site was under a normal South-easterly swell $<1 \mathrm{~m}$, with a good visibility $(>15 \mathrm{~m})$. Three to four Lemon sharks were quietly swimming (without appearing nervous) around a cage (containing fish bait) that was lying on the bottom. The dive master was positioned about $10 \mathrm{~m}$ from the cage, focusing on a marine turtle in the water column that he wanted to photograph. He was not wearing gloves and held his waterproof camera housing with the right hand as his left hand was holding the strobe at the end of a metal $\mathrm{arm}$. As he was moving his hand in order to properly position the strobe for the next photo, a $2.5 \mathrm{~m}$ TL male shark came from behind him and firmly grabbed his left hand for few seconds. It took two attempts to extract his hand from the shark's mouth. The bite left relatively superficial wounds on the top and the side of the left hand, with no lasting after-effects following surgery (Figure 3B).

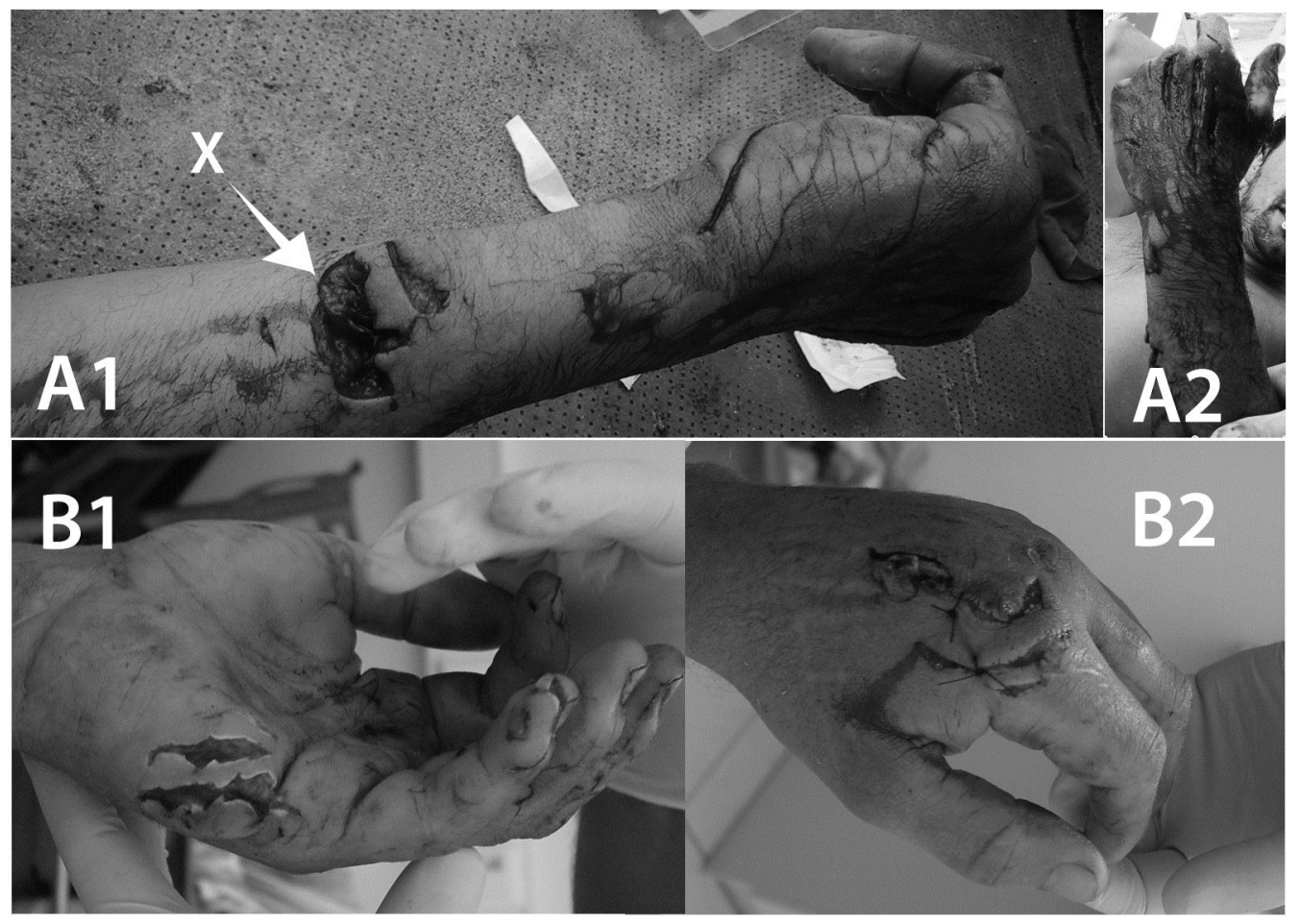

Figure 3: (A) Photographs (before surgery) of the 2004 bite on the left hand, showing (A1) the impression of the teeth from the lower jaw that caused a deep wound the forearm $(\mathrm{X})$ for providing support as the teeth from the upper jaw tore flesh from the top of the hand (A2), leaving parallel prototypic wounds for dagger like shark teeth. (B) Photographs (after surgery) of the 2008 bite on the left hand, showing (B1 and B2) two major parallel elongated wounds left by two contigous teeth in both sides

In both cases, the surgery restricted to wound decontamination and closure as there was not any tendon rupture

\section{Discussion}

The bites described here are part of a number of bites on divers since the mid-1980s (when shark feeding was initiated in Moorea Island). They did not strictly happened during a usual commercial shark diving situation but nothing suggests that the absence of tourist divers may have carried out any specific behaviour of the Lemon sharks. We then believe that these two cases can provide a useful analysis that can support an acceptable generalization. They are two of the very few bites about which it was possible to gather reliable data in order to conduct this analysis. Bites (whatever their severity) in the context of shark diving definitely happen regularly $[11,18]$, but diving operators are very reluctant to communicate and report them, due to the risk of a strong negative impact on ecotourism activity and subsequent economic impacts [1].

\section{Accidental nature of the bites}

The two bites described in this study occurred in presence of witnesses and were not fatal; there is therefore no doubt about the identification of the shark species. The features of the wounds are consistent with the characteristics of the thin and sharp teeth of Lemon shark, in particular the two parallel wounds that are displayed in Figure 3A2 and the three deeper ones in Figure 3B1. These wounds are both superficial and the shape of the grooves reflects the movement of the hand as it was extracted from the mouth of the shark (N. Buray Pers. Comm.). Such wounds would not be possible unless the pressure of the bite is quite light and short in 
duration, indicating that both bites should be considered as "ingestion" bites corresponding to ram feeding [14]. In the case of "manipulation" bites, with a more feeding and predatory purpose, the wounds would be deeper and much more severe. This brings us to consider these bites as "accidental" rather than based on other motivation such as feeding on human flesh (as a food substitute to natural food such as fish flesh) or agonistic behavior toward a diver. Our deduction is consistent with the hypothesis that the two sharks were not expecting to find any resistance when they bit the hands, rather looking to seize a loose piece of bait. This expectation may be linked to the long-term effects of shark feeding.

\section{Specific effects of 'hand-feeding' on shark behaviour}

Provisioning uses the animals' attraction to food to offset or neutralize their aversion to humans [19]. The animals tolerate a human presence in return for the feeding opportunity available to them. In that sense, one of the first effects of provisioning will be 'habituation' and 'tolerance' [20], as it happened in Moorea island through the repetitive provisioning of sharks, year after year. Based on the hypothesis that adult Sicklefin Lemon sharks would need the same amount of food as the Caribbean species N. brevirostris, which removes nearly $1.5 \mathrm{~kg}$ of fish daily $\left(1.6 \times 10^{6}\right.$ calories) to provide for its vital activities [21], the amount of inanimate food provided daily would be far from enough to create a dependency of Lemon sharks to provisioning. However, as some animals were regularly rewarded through the hand feeding, this type of rewarding provisioning also had a positive reinforcement effect, and a slow process of 'sensitization' [20] could well apply to some animals, in particular the dominant ones [9].

Studies conducted on White sharks in South Africa showed that general conditions are rarely met for sharks to develop a learned response, indicating that moderate levels of tourism activity may not have a broad impact on shark behaviour across a wide range of space and time scales [5]. However where rewards are made readily available and there is a definite learning effect, greater risks of altering behaviour of target animals are likely to occur [22]. During the implementation of hand-feeding, the sharks easily identify the end of the arms (the hands) as a potential source of food. In addition, feeders often attract the attention of the shark by shaking the hand holding the food. In two alternative forced-choice experiments, in which choosing the designated positive stimulus was food-reinforced, it was recently shown that fish are able to distinguish biological motion patterns [23]. Therefore, the hand shaking associated with food reward can be considered as a strong visual stimulus for the sharks. Beside the association of food with the divers' hands, this specific human behaviour then leads the shark to associate the movement of hands with a food reward. We strongly believe that for the two documented bites, the visual stimulus was dominant and facilitated by uncovered skin, which can easily be confounded with any fish flesh, as no clear evidence of anything other than monochromatic vision has been shown for the Lemon shark [24]. In the context of the second accident, the movements of the arm and the hand on the strobe were probably a determining factor for stimulating the accidental bite, by incidentally simulating a hand-feeding stimulus, as described for a similar bite in February 2013 on a diver's hand in Bora-Bora [18].

\section{The role of hand-feeding in accidental bites}

It was recently proved that an altered behaviour in the Catshark Scyliorhinus canicula could be reversed after a 3-week interruption of the conditioning stimulus [25]. One could thus expect that the curtailing of hand feeding in 2004 should have prevented any other accidental bite. However, the change of feeding practice was only partial, as other operators were still hand feeding. In spite of being irregular, this hand feeding should also be considered as a facilitating factor for the 2008 accidental bite. As another convincing fact, even if it does not concern the Lemon shark, the dive master that started the feeding in Moorea island confessed that he was accidently bitten six times by Blacktip sharks and once by a Grey reef shark during artificial provisioning from the mid-1980s to the early 2000s (P. Molle Pers. Comm.). These figures are consistent with the ratio provided by Maillaud, et al. [11] in terms of species prevalence in accidental bites and could be explained by the higher mobility and speed of these smaller bodied sharks that limit an avoidance reflex by the scuba diver, compared to the larger and slower Lemon sharks. Based on that same study, the hand feeders have around eight times more chance of being bitten by a shark than diving spectators; however, the remaining $12 \%$ of tourist divers that might be victim of such bites could consider, with strong evidence based on our analysis, that the diving companies that are practicing hand feeding should bear responsibility.

\section{Aknowledgement}

The authors wish to thanks the several dive masters that kindly provided the information regarding the development of sharkfeeding in Moorea island and the accidental bites, in particular Nicolas Buray who was victim of the two accidental bites that are described in this paper.

\section{References}

1. Topelko KN, Dearden P (2005) The shark watching industry and its potential contribution to shark conservation. J Ecotourism 4: 108 -28.

2. Gallagher AJ, Hammerschlag N (2011) Global shark currency: the distribution, frequency, and economic value of shark ecotourism. Curr Iss Tourism 14: 797812 .

3. Clua E, Buray N, Legendre P, Mourier J, Planes P (2011) Business partner or simple catch? The economic value of the sicklefin lemon shark in French Polynesia. Mar Freshwater Res 62: 764-70.

4. Dobson J (2006) Sharks, wildlife tourism, and state regulation. Tourism Mar Env 3: 15-23.

5. Laroche RK, Kock AA, Dill LM, Oosthuizen WH (2007) Effects of provisioning ecotourism activity on the behaviour of white sharks Carcharodon carcharias. Mar Ecol Prog Ser 338: 199-209. 
6. Meyer CG, Dale JJ, Papastamatiou YP, Whitney NM, Holland KN (2009) Seasonal cycles and long-term trends in abundance and species composition of sharks associated with cage diving ecotourism activities in Hawaii. Env Conserv 36: 1-18.

7. Bruce BD, Bradford RW (2013) The effects of shark cage-diving operations on the behaviour and movements of white sharks, Carcharodon carcharias, at the Neptune Islands, South Australia. Mar biol 160: 889-907.

8. Techera EJ, Klein N (2013) The role of law in shark-based eco-tourism: Lessons from Australia. Mar Pol 39: 21-8.

9. Clua E, Buray N, Legendre P, Mourier J, Planes P (2010) Behavioural response of sicklefin lemon sharks Negaprion acutidens to underwater feeding for ecotourism purposes. Mar Ecol Prog Ser 414: 257-66.

10. Clarke C, Lea JSE, Ormond RFG (2011) Reef-use and residency patterns of a baited population of silky sharks, Carcharhinus falciformis, in the Red Sea. Mar and Freshw Res 62: 668-75.

11. Maillaud C, Van Grevelynghe G (2005) Attacks and shark bites in French Polynesia: Shark attacks and bites in French Polynesia. J Euro des Urgences 18: 37-41.

12. Buray N, Mourier J, Planes P, Clua E (2009) Underwater photo-identification of sicklefin lemon sharks, Negaprion acutidens, at Moorea (French Polynesia). Cybium 33: 21-7.

13. Compagno LJV (1984) Sharks of the World. An Annotated and Illustrated Catalogue of Shark Species Known to Date: Part 2. Carcharhiniformes FAO Fisheries Synopsis 125, 2: 251-655.

14. Motta PJ, Hueter RE, Tricas TC (1991) An electromyographic analysis of the biting mechanism of the lemon shark, Negaprion brevirostris: functional and evolutionary implications. J of Morphol 210: 55-69.

15. Motta P, Tricas T, Summers R (1997) Feeding mechanism and functional morphology of the jaws of the lemon shark Negaprion brevirostris (Chondrichthyes, Carcharhinidae). The J of Exp Biol 200: 2765-80.

16. Tricas TC, McCosker JE (1984) Predatory behavior of the white shark (Carcharodon carcharias), with notes on its biology. Proc Calif Acad Sci 43: 221-38.

17. Clua E, Buray N, Legendre P, Mourier J, Planes P (2010) Effects of provisioning on shark behaviour: Reply to Brunnschweiler \& McKenzie. Mar Ecol Prog Ser 420: $285-8$.

18. Clua E (2013) Managing bite risk for divers during shark feeding ecotourism: a case study from Bora-Bora (French Polynesia). Technical report. Haut-commissariat de la République française en Polynésie française 11.

19. Knight J (2009) Making wildlife viewable: habituation and attraction. Society and Animals 17: 167-84.

20. Bejder L, Samuels A, Whitehead H, Finn H, Allen S (2009) Impact assessment research: use and misuse of habituation, sensitisation and tolerance in describing wildlife responses to anthropogenic stimuli. Mar Ecol Prog Ser 395: 177-85.

21. Gruber SH (1982) Role of the lemon shark, Negaprion brevirostris (Poey) as a predator in the tropical marine environment: a multidisciplinary study. Florida Sci 45: 46-75.

22. Guttridge TL, Myrberg AA, Porcher IF, Sims DW, Krause J (2009) The role of learning in shark behaviour. Fish and Fisheries 10: $450-69$.

23. Schluessel V, Kortekamp N, Cortes JO, Klein A, Bleckmann H (2015) Perception and discrimination of movement and biological motion patterns in fish. Anim cogn 18: 1077-91.

24. Van-Eyk SM, Siebeck UE, Champ CM, Marshall J, Hart NS (2011) Behavioural evidence for colour vision in an elasmobranch. J Exp Biol 214: $4186-92$.

25. Kimber JA, Sims DW, Bellamy PH, Gill AB (2014) Elasmobranch cognitive ability: using electroreceptive foraging behaviour to demonstrate learning, habituation and memory in a benthic shark. Anim Cogn 17: 55-65.

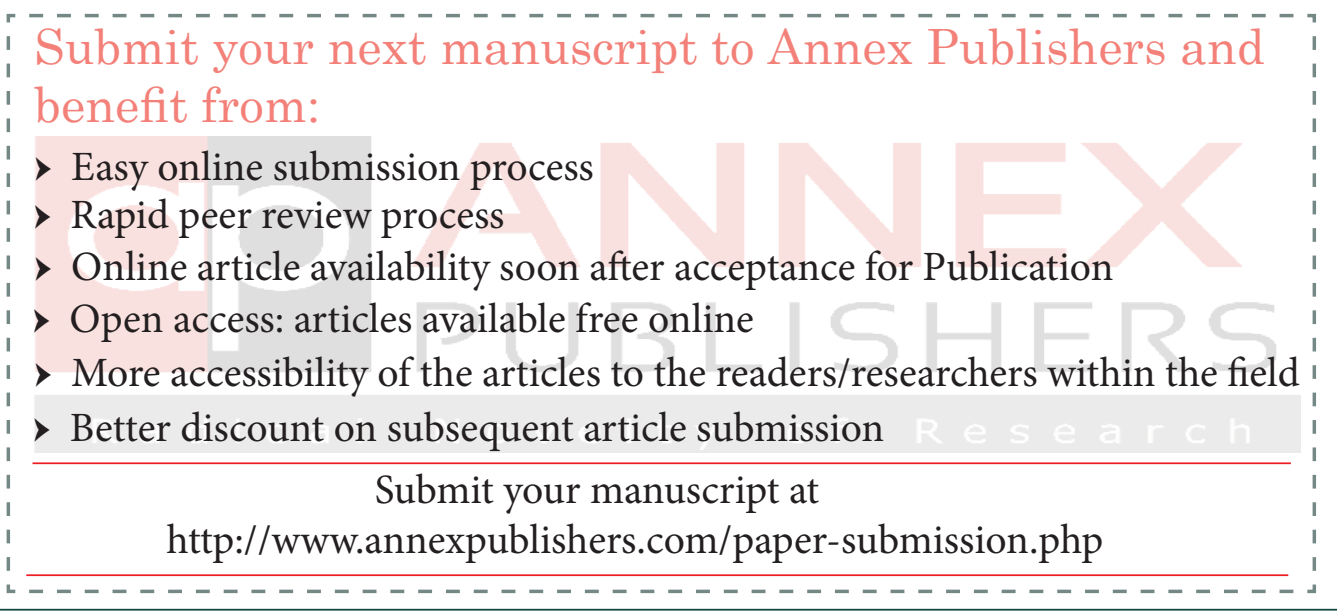

